\title{
Clinical characteristics of 9 cancer patients with SARS-CoV-2 infection
}

\author{
Yong Zeng ${ }^{1}$, Bo Zhang ${ }^{2}$, Xufeng Zhang ${ }^{1}$ and Cunjian $\mathrm{Yi}^{\mathrm{i}^{*}}$
}

\begin{abstract}
In December 2019, a cluster of pneumonia cases was caused by the Severe Acute Respiratory Syndrome coronavirus 2 (SARS-CoV-2) in Wuhan, China. Cancer patients are a special group, the immunity of them will be suppressed because of various anti-tumor treatments, and the risk of infection will be greatly increased, so we will report clinical features of 9 cancer patients with SARS-CoV-2 infection. 5 (56\%) patients were ordinary type, 3 (33\%) were severe type, and $1(11 \%)$ was critical type. A total of 8 patients received combined therapy of traditional Chinese medicines and western medicines. From the clinical outcomes of these 8 patients, western combined therapy of traditional Chinese medicine was indeed an effective treatment method. D-dimmer rise, infection index rise, and chest CT(computed tomography) progression may be clinical warning indicators for severe patients, in our study, more $50 \%$ of patients had elevated levels of these indicators, but only $44 \%$ (including the dead) of patients had received treatment in the intensive care unit. 5 (56\%) ordinary type patients had been discharged, while the 1 (11\%) critical type patient died 3 days after admission. Cancer comorbidity seems to have no direct relationship with severe events, and the combination of traditional Chinese medicine and western medicine may be effective in the prevention and treatment of novel coronavirus-infected pneumonia (NICP).
\end{abstract}

Keywords: Cancer, SARS-CoV-2, Clinical characteristics, Outcomes

\section{Background}

In December 2019, a cluster of pneumonia cases caused by the SARS-CoV-2 occurred in Wuhan, Hubei province $[1,2]$. Now it has developed into an international public health emergency. However, in this new outbreak of novel NCIP there is a special population that cannot be ignored-cancer patients. After receiving various antitumor treatments, the immunity of cancer patients will be suppressed, and the risk of infection will be greatly increased [3-6] .Liang found that cancer patients in SARS-CoV-2 infection had poorer outcomes [7]. However, neither Yang Xia [8] nor Hanping Wang [9] through there was a strong link between cancer and SARS-CoV-2 infection. Here, so we will report the clinical features of

\footnotetext{
*Correspondence: cunjiany@163.com

${ }^{1}$ The First People's Hospital Affiliated to Yangtze University in Jingzhou, 8 Hangkong Road, Jingzhou, Hubei, China

Full list of author information is available at the end of the article
}

cancer patients with SARS-CoV-2 infection to provide further knowledge of this disease.

\section{Data collection}

This study was approved by the institutional ethics board of Yangtze University. A retrospective, single-institutional review of cancer patients with SARS-CoV-2 infections was conducted between January 23 and February 29 2020, at the First People's Hospital affiliated with Yangtze University in Jingzhou, China. Basic information, clinical manifestations, laboratory, medical imaging and outcome dates were collected from patients' medical records and were exhibited in Additional file 1: Appendix 1, Additional file 2: Appendix 2, Additional file 3: Appendix 3 and Additional file 4: Appendix 4 respectively. The median time was exhibited in Fig. 1, included from onset of symptoms to SARS-CoV-2 positivity, from onset of symptoms to intensive care unit admission, from SARS-CoV-2 positive to negative. As of March 3, 2020,

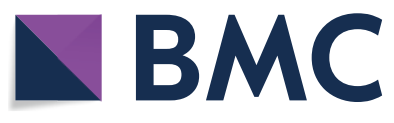

c) The Author(s) 2020. This article is licensed under a Creative Commons Attribution 4.0 International License, which permits use, sharing, adaptation, distribution and reproduction in any medium or format, as long as you give appropriate credit to the original author(s) and the source, provide a link to the Creative Commons licence, and indicate if changes were made. The images or other third party material in this article are included in the article's Creative Commons licence, unless indicated otherwise in a credit line to the material. If material is not included in the article's Creative Commons licence and your intended use is not permitted by statutory regulation or exceeds the permitted use, you will need to obtain permission directly from the copyright holder. To view a copy of this licence, visit http://creativeco mmons.org/licenses/by/4.0/. The Creative Commons Public Domain Dedication waiver (http://creativecommons.org/publicdomain/ zero/1.0/) applies to the data made available in this article, unless otherwise stated in a credit line to the data. 


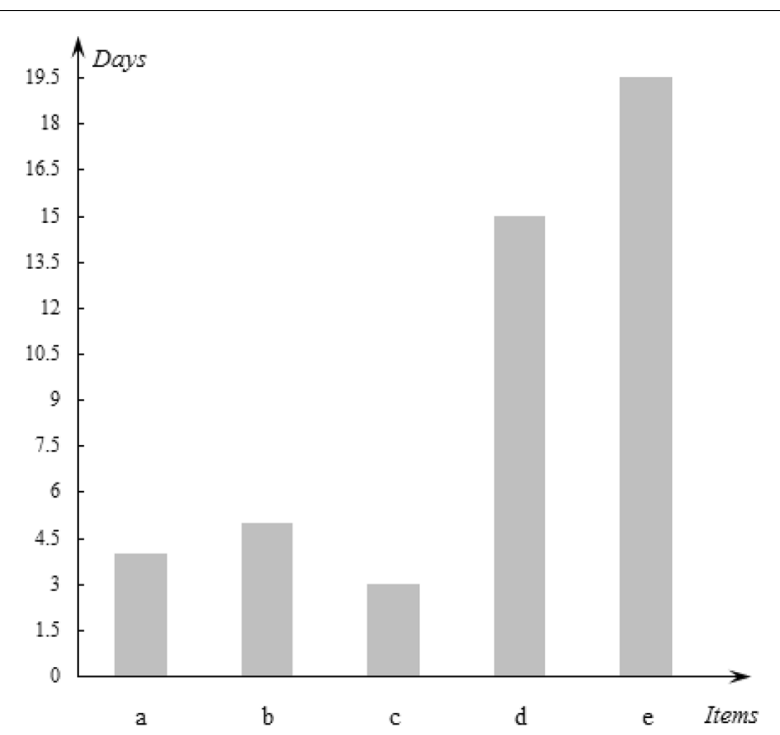

Fig. 1 The median time from onset of symptoms: a to first hospital admission was 4 (1-15) days; $\mathbf{b}$ to 2019-nCoV positive was 5 (2-20) day; $\mathbf{c}$ to first chest CT images was $3(1-10)$ days; $\mathbf{d}$. to intensive care unit admission was 15 (2-23)days; e the median time from nCoV positive to negative was 19.5 (2-26)days

the novel coronavirus detection of $8(100 \%)$ patients was negative. Outcomes were followed up until March 8, 2020.

\section{Treatment regimen}

This disease belongs to the category of traditional Chinese medicine epidemic diseases, and caused by the plague poison. Studies [10] found that the combination of traditional Chinese medicine and western medicine was effective in the prevention and treatment of NICP in all stages, and the response rate of symptoms such as fever, cough and fatigue were significantly increased in ordinary patients after taking lianhua qingwen granules. In the critical stage, modern medicine approaches can play a powerful role in patients' life support and the control of complications, xuebijing injection combination with modern medicine approaches can improve the cure rate. In addition, compared with the western medicine group, the chinese-western combined treatment group had shorter test negative conversion time, higher symptom improvement rate and shorter hospital stay. Therefore, the combination of Chinese medicine and western medicine was effective in the treatment of NICP. In our study, a total of 8 patients received combined therapy of traditional Chinese medicines and western medicines. 8 (89\%) patients received oral antiviral treatment using Lianhua Qingwen granules and Arbidol. 3 severe patients were given additional intravenous Xuebijing injection. In addition, through the different stages of COVID-19 infection of the body dialectical, based on Lung Cleaning and Detoxifying Decoction, flexible use of Chinese medicine prescription. All patients were given antibiotics. 8 (89\%) patients were given a combination of antibiotic treatments. 5 (56\%) patients were given intravenous methylprednisolone. Immunoglobulin was provided to 3 (33\%) patients (10-14 days). 7 (78\%) patients were treated with oxygen inhalation (nasal catheter or mask), 4 (44\%) were treated with high-flow oxygen inhalation, and one patient used non-invasive mechanical ventilation. From the clinical outcomes of these 8 patients, western combined therapy of traditional Chinese medicine was indeed an effective treatment method, but due to the limited case data, more clinical practice data were needed to evaluate.

\section{Clinical outcomes}

Of the 9 patients, 5 (56\%) patients were ordinary type, $3(33 \%)$ were severe type, and $1(11 \%)$ was critical type. 1 patient (critical type, 82 years old) died from multiple organ failure, and the interval time from onset of symptom to death was 3 days. 5 patients (ordinary type) had been discharged, and their median time of hospitalization was 26 (7-29) days. All other patients were still in hospital. According to the pneumonia diagnosis and treatment protocol for novel coronavirus infection released by the National Health Commission (version 6), $\mathrm{D}$-dimmer rise, infection index rise, and chest CT progression may be clinical warning indicators for severe patients. In our study, a majority of patients had differing degrees of increased infection index, which may represent more prominent inflammation. $78 \%$ of patients had increased D-dimmer, and previous studies had found that D-dimmer increase was related to severity of illness $[11,12] .56 \%$ of patients showed signs of multiple mottling and ground-glass opacity, in other studies, earlystage chest CT examination mostly showed multiple, small patch-like shadows and interstitial changes [13], which may indicate that in cancer patients with SARS$\mathrm{CoV}-2$ infections lung lesions progressed faster. But only $44 \%$ (including the dead) of patients had received treatment in the intensive care unit. Additionally, of the 5 cancer patients with SARS-CoV-2 infections receiving anti-tumor treatment in the last year, only $2(40 \%)$ also had been diagnosed as severe type, with the other $(60 \%)$ diagnosed as ordinary type. This seems to indicate that cancer comorbidity may have no direct relationship with severe events.

\section{Conclusion}

By analyzing 9 cancer patients with SARS-CoV-2 infection, cancer comorbidity seems to have no direct relationship with severe events, and the combination of traditional Chinese medicine and western medicine may 
be effective in the prevention and treatment of NICP. So the study may offer some suggestions about nurse and treatment of cancer patients with SARS-CoV-2 infection.

\section{Supplementary information}

Supplementary information accompanies this paper at https://doi. org/10.1186/s13020-020-00328-8.

\author{
Additional file 1. Cancer related history and treatment of cancer patients \\ with 2019-nCov infection.
}

Additional file 2: Table S1. General information and Clinical manifestations of cancer patients with 2019-nCoV infection.

Additional file 3: Table S2. Laboratory dates of cancer patients with 2019-nCoV infection

Additional file 4: Table S3. Chest CT images of cancer patients with 2019-nCoV infection.SARS-CoV-2: Severe Acute Respiratory Syndrome coronavirus 2; NCIP: Novel coronavirus-infected pneumonia; CT: Computed tomography; COVID-19: Corona Virus Disease 2019.

\section{Acknowledgements}

We thank all the patients who participated in this study, their families, and the investigators. We thank all the medical worker who participated in the outbreak of NCIP.

\section{Authors' contributions}

YZ and CY had full access to all of the data in the study and take responsibility for the integrity of the data and the accuracy of data analysis. Conception and design: $Y Z$ and $C Y$. Acquisition, analysis, or interpretation of data: $Y Z, X Z$, $B Z, C Y$. Drafting of the manuscript:YZ. Critical revision of the manuscript for important intellectual content: YZ, BZ. Statistical analysis: YZ, BZ, XZ. Supervision: CY. All authors read and approved the final manuscript.

\section{Funding}

1. Key project of hubei provincial health commission (WJ2017Z024), 2. Hubei provincial health commission medical college special (WJ2018H175)

\section{Availability of data and materials}

The datasets used and analysed during the current study are available from corresponding author on reasonable request.

\section{Ethics approval and consent to participate}

This study was approved by the institutional ethics board of Yangtze University. Informed consent of the study was waived because of the retrospective nature and the analysis used anonymous clinical data.

\section{Consent for publication}

The analysis used anonymous clinical data.

\section{Author details}

${ }^{1}$ The First People's Hospital Affiliated to Yangtze University in Jingzhou, 8 Hangkong Road, Jingzhou, Hubei, China. ${ }^{2}$ Shanghai Chest Hospital Affiliated To Shanghai Jiaotong University, Shanghai, China.

Received: 30 March 2020 Accepted: 4 May 2020

Published online: 14 May 2020

\section{References}

1. Novel Coronavirus (2019-nCoV). Geneva: World Health Organization, 2019. https://www.who.int/emergencies/diseases/novel-coronaviru s-2019. [Accessed Jan 26, 2020].

2. Lu H, Stratton CW, Tang YW. Outbreak of pneumonia of unknown etiology in Wuhan China: the mystery and the miracle. J Med Virol. 2020. https ://doi.org/10.1002/jmv.25678 Published online Jan 16.

3. Kamboj M, Sepkowitz KA. Nosocomial infections in patients with cancer. Lancet Oncol. 2009;1 0:589-97.

4. $L i J Y$, Duan $X F$, Wang $L P$, et al. Selective depletion of regulatory $T$ cell subsets by docetaxel treatment in patients with nonsmall cell lung cancer. J Immunol Res. 2014;2014:286170.

5. Longbottom ER, Torrance HD, Owen HC, et al. Features of postoperative immune suppression are reversible with interferon gamma and independent of interleukin-6 pathways. Ann Surg. 2016;264:370-7.

6. Sica A, Massarotti M. Myeloid suppressor cells in cancer and autoimmunity. J Autoimmun. 2017;85:117-25.

7. Liang Wenhua, Guan Weijie, Chen Ruchong, et al. Cancer patients in SARS-CoV-2 infection: a nationwide analysis in China. Lancet Oncol. 2020;21:335.

8. Xia Yang, Jin Rui, Zhou Jing, et al. Risk of COVID-19 for cancer patients. Lancet Oncol. 2020;21:280.

9. Wang Hanping, Zhang Li. Risk of COVID-19 for cancer patients. Lancet Oncol. 2020;21:e181.

10. State administration of traditional Chinese medicine. Press conference on the prevention and control of the epidemic in hubei province. [2020-0215]. http://bgs.satcm.gov.cn/gongzuodongtai/2020-02-15/13088.html.

11. Zhang JJ, Dong X, Cao YY, et al. Clinical characteristics of 140 patients infected with SARS-CoV-2 in Wuhan China. Allergy. 2020. https://doi. org/10.1111/all.14238.

12. Wang D, Hu B, Hu C, Characteristics Clinical, et al. Clinical Characteristics of 138 hospitalized patients with 2019 novel coronavirus-infected pneumonia in Wuhan. JAMA. 2019;323:1061.

13. Liu K, Fang YY, Deng Y, et al. Clinical characteristics of novel coronavirus cases in tertiary hospitals in Hubei Province. Chin Med J. 2020. https://doi. org/10.1097/CM9.00000000000000744.

\section{Publisher's Note}

Springer Nature remains neutral with regard to jurisdictional claims in published maps and institutional affiliations.

\section{Competing interests}

None.

Ready to submit your research? Choose BMC and benefit from:

- fast, convenient online submission

- thorough peer review by experienced researchers in your field

- rapid publication on acceptance

- support for research data, including large and complex data types

- gold Open Access which fosters wider collaboration and increased citations

- maximum visibility for your research: over $100 \mathrm{M}$ website views per year

At BMC, research is always in progress.

Learn more biomedcentral.com/submissions 